\title{
BIOÉTICA: INTERDISCIPLINARIEDAD, INTERCULTURALIDAD, INTERDISCURSIVIDAD
}

\author{
Fernando Lolas Stepke ${ }^{1}$
}

Acta Bioethica se ha consolidado como una tribuna que armoniza disciplinas, culturas y discursos. No en vano, mientras dirigí el Programa o Unidad de Bioética en la Organización Panamericana de la Salud (OPS) —entre 1998 y 2010 - nuestra definición no pretendía apuntar a un presunto "corpus" de saber, con las especificidades que ello hubiera implicado, sino al diálogo. Como instrumento fundante de una práctica que esperaría hacer mejor la vida y satisfacer expectativas de personas en sociedades en proceso de perfeccionar la justicia, éste es su basamento central ${ }^{2}$.

Al observar el contenido de los trabajos de esta edición ello es evidente. Algunos textos enfocan el plano de las relaciones interpersonales. Otros aluden a la posibilidad de proponer ideas útiles en campos tan diversos como la educación y los estudios ambientales.

Con ello se destaca el factor "interés". Inter-Esse, lo que está entre sujetos, disciplinas, culturas, discursos, narraciones. Este desafío es mucho más interesante que politizar el discurso bioético para hacerlo cumplir funciones en agendas de reivindicación o resaltar un presunto papel filantrópico o "protector" de minorías desvalidas. Esto en sí mismo no es negativo, pero para funciones de ese orden existen procedimientos lisa y llanamente políticos. Ellos no exigen revestirse de apariencia académica o cultivarse en círculos intelectuales. La bioética, como construcción disciplinaria, no puede ser simple herramienta para combatir opresiones o imponer ideologías. Si la tolerancia significa algo, es precisamente formar criterios que puedan transparentarse y exponerse a la confrontación en la interfaz entre conocimiento y experiencia ${ }^{3}$.

La degradación del discurso bioético ocurre en muchas formas. Dos, sin embargo, son perceptibles en el escenario latinoamericano ${ }^{4}$.

La primera, ya lo observamos, es la politización. Denunciantes vocingleros de anomalías sociales, adherentes a regímenes aparentemente democráticos, oportunistas que buscan medrar con los temores y las debilidades de la gente, entre otros especímenes humanos, dicen hacer bioética. El resultado es una suerte de intolerancia malsana que en ocasiones anteriores hemos comentado. Su perpetuación no contribuye a enaltecer la intelectualidad latinoamericana.

La segunda degradación ocurre por el proceso burocratizador que se instala en instituciones y conciencias. A veces la conformación de comités de bioética permite anticipar una maraña regulatoria y un papeleo que, lejos de iluminar, abruma a los que deben someterse a sus decisiones 5 .

En ambas formas de corrupción de lo bioético en las instituciones aparece el problema del poder, escasamente discutido en relación con la institucionalización de la bioética. Un comité es, adecuada-

\footnotetext{
${ }^{1}$ Profesor Titular, Universidad de Chile. Secretario General, Asociación Mundial de Psiquiatría Social. Director, Acta Bioethica. Correspondencia: flolas@uchile.cl

${ }^{2}$ Lolas F. Bioética: pasado, presente, futuro. Una perspectiva personal. Bioethikós (Sao Paulo) 2014; 8(4): 456-463.

${ }^{3}$ Lolas F. El valor instrumental del discurso bioético. Su relevancia en el ámbito de los derechos humanos.Jurisprudencia Argentina (Número Especial de Bioética II) 2017; 56-63.

${ }^{4}$ Lolas F. Ciencias sociales empíricas y bioética. Reflexiones de circunstancia y un epílogo para latinoamericanos. Acta Bioethica (Santiago de Chile) 2002; 8(1): 47-53.

${ }^{5}$ Lolas F. Comités de ética de la investigación: una solución en busca de problemas. Revista Chilena de Reumatología 2007; 23 (1): 2 -4.
} 
mente manejado, un núcleo de poder en una institución. Podría tomar decisiones que afecten selectivamente a grupos o personas. Podría dilatar acuerdos o hacer inviables algunas investigaciones. Todo bajo la apariencia de buenas causas, al amparo de un ideario benefactor ${ }^{6}$. Especialmente en el área ambiental y en ciertas formas de investigación social y clínica, apegarse a la letra de ciertas pautas y dar con ello interpretaciones antojadizas puede ser una forma maligna de degradación de la herramienta bioética.

Otro aspecto que el desarrollo del discurso bioético exige considerar es el cultural. No solamente las dimensiones macro de la cultura, aquellas que tipifican poblaciones y colectivos amplios, unidos por lenguaje y costumbre 7 . También hay culturas institucionales, locales, acotadas, que merecen examen y tolerancia cuando de intervenir o decidir se trata. No sirven los trasplantes de decisiones. Lo que en la gran empresa puede parecer aceptable puede no permitirse en comunidades académicas, aunque manifiesten fines cognoscitivos semejantes. No debe olvidarse que palabras como "investigación”, "innovación", "progreso" son tan polisémicas que solamente entendiendo los contextos de su uso puede apreciarse qué ocurrirá con las decisiones que se tome.

\section{Para finalizar, una advertencia}

La misma amplitud y polisemia del discurso bioético, superando las cuales cabría esperar una fisonomía disciplinaria inmune a la degradación, han contribuido a que nuestra revista sea conocida y apreciada en vastos ambientes. Al mismo tiempo, ha sido víctima de maniobras criminales que, plagiando el sitio web de la revista, invitan a autores a enviar manuscritos cobrando por publicar en asuntos que nada tienen que ver con el tema bioético. Al concluir esta nota preliminar con una advertencia nos insertamos en el mundo real y quisiéramos la colaboración de nuestra lectoría para detener este abuso, que malogra la configuración de una red social de genuinos interesado en la bioética

\footnotetext{
${ }^{6}$ Rodriguez E, Lolas F. The topic of research integrity in Latin America. Bioethikos (Sao Paulo) 2011; 5(4): 362-368.

${ }^{7}$ Lolas F. Hacia una bioética cultural. Bioethics Update (México) 2017; 3(1): 32-44.
} 